\title{
DA QUEDA DO MODELO DE DESENVOLVIMENTO FORDISTA À ASCENSÃO DA ACUMULAÇÃO FLEXÍVEL
}

\section{FALL OF THE MODEL OF DEVELOPMENT OF ASCENSION FORDIST TO FLEXIBLE ACCUMULATION}

\author{
Francisco José Lima Sales ${ }^{1}$
}

\section{RESUMO}

O texto aborda a problemática apresentada pelas profundas transformações ocorridas no mundo do trabalho e na estrutura do Estado regulador, voltado para o bem-estar social. Objetiva discutir o processo de reestruturação produtiva capitalista, ocorrido a partir das últimas décadas do século passado, e as suas conseqüências sobre o modelo de desenvolvimento à época dominante, o fordismo. Para caracterizar a crise do modelo de desenvolvimento fordista, são utilizados aspectos da perspectiva adotada pela escola francesa da regulação, com destaque das principais características deste modelo que emergiu no pós-guerra e que adquiriu configuração mundial no ocidente industrializado, e, principalmente, do processo de reestruturação industrial que ocorreu no âmbito das economias centrais e as características do novo modelo de desenvolvimento.

PALAVRAS-CHAVE: Fordismo - Estado Regulador - Modelo de Desenvolvimento -Reestruturação Produtiva.

\section{ABSTRACT}

The text addresses the problems presented by the profound changes occurring in the world of work and structure of the regulatory state, for the well-being. Aims to discuss the process of capitalist production restructuring, which occurred from the last decades of the last century, and its consequences on the 
development model prevailing at the time, Fordism. To characterize the crisis of the Fordist model of development, are used aspects of the perspective adopted by the French school of regulation, particularly of the main characteristics of this model that emerged in the postwar world configuration and acquired in the industrialized West, and especially the process industrial restructuring that occurred within the core economies and the characteristics of the new development model.

KEYWORDS: Fordism - the state regulator - the development model restructuring.

\section{INTRODUÇÃO}

Este trabalho é resultado de uma apreensão fundamentalmente teórica da problemática apresentada pelas profundas transformações ocorridas no mundo do trabalho e na estrutura do Estado regulador - voltado para o bemestar social -, possibilitada pelas discussões suscitadas no transcorrer da disciplina "Estado e Desenvolvimento", do Programa de Pós-Graduação em Ciências Sociais da Universidade Federal do Rio Grande do Norte - UFRN, ministrada pelos professores Willington Germano e Eleonora Tinoco.

Assim, objetiva-se neste trabalho discutir o processo de reestruturação produtiva capitalista, ocorrido a partir das últimas décadas do século passado, e as suas conseqüências sobre o modelo de desenvolvimento à época dominante, o fordismo, além das repercussões dessas transformações para a formação e qualificação dos trabalhadores, em particular as determinações sobre o arcabouço jurídico-educacional brasileiro, enfocando a relação entre educação básica e educação profissional.

Nesta exposição, para delinear a crise do modelo de desenvolvimento fordista, serão utilizados aspectos da perspectiva adotada pela escola francesa da regulação ${ }^{2}$, com destaque das principais características deste modelo que emergiu no pós-guerra e que adquiriu configuração mundial no ocidente industrializado, e, principalmente, do 
processo de reestruturação industrial que ocorreu no âmbito das economias centrais e as características do novo modelo em desenvolvimento.

Em que pese o debate e as produções acadêmicas nas áreas da sociologia e da economia do trabalho já se desenvolverem há algum tempo, percebe-se a existência de uma grande polêmica entre os pesquisadores quanto à questão da inevitabilidade da universalização das inovações presentes no atual processo de reestruturação, no âmbito dos países periféricos $^{3}$ da América Latina, em particular no Brasil.

Nesse contexto, que implicou demandas crescentes feitas aos trabalhadores pelo desenvolvimento técnico, bem como pela precária situação educacional da população brasileira que não atenderia, segundo alguns autores, sequer ao atual sistema de produção, uma reflexão sobre a necessidade de reformas no sistema educacional foi realizada.

Dessa maneira, a educação passou a ser vista como um importante fator de produção, à medida que a posse de novas competências repassadas pela escola básica possibilitaria a aplicação de inovações tecnológicas capazes de atender aos objetivos da produção, ou seja, a maior produtividade e qualidade.

Todavia, a realidade mostra que ao mesmo tempo em que se observam as exigências do capital por novas competências, ocorre o declínio do número de postos de trabalho na indústria, o aumento significativo do setor terciário e o recrudescimento do trabalho precário, que, somado à drástica redução do papel social do Estado promove a eliminação dos direitos sociais, o desmonte da seguridade, sobretudo da previdência social, o enfraquecimento do poder de representação dos trabalhadores e a desregulamentação e arrocho dos salários.

Tal fenômeno, segundo se pode perceber, não se apresenta como uma estratégia homogênea. A consulta à bibliografia especializada revela situações complexas e, ao mesmo tempo, divergentes, já que o processo de flexibilização do setor produtivo e do trabalho apresenta diferenças entre as várias experiências existentes, ou melhor, é pouco provável que o modelo 
japonês possa ser aplicado na realidade brasileira da mesma forma como o foi naquele país.

Por fim, tendo em vista a complexidade do tema, as idéias aqui expostas pretendem tão somente problematizar os estudos já realizados, buscando com isso o aprofundamento da discussão.

\section{CONSTITUIÇÃO E DESEVOLVIMENTO DO MODERNO LEVIATÃ: O ESTADO DO BEM ESTAR SOCIAL}

O enfoque da abordagem politicista da escola de regulação ${ }^{4}$ sobre 0 Estado capitalista contemporâneo indica que entre os anos 1945 e $1975^{5}$ consolidou-se, nas sociedades industriais da Europa e Estados Unidos, uma utopia de uma sociedade do trabalho. (FARIAS, 1996)

Tal idealização da tendência politicista ${ }^{6}$ fundava-se na tese de que a forma de Estado apropriado ao regime fordista de acumulação correspondia ao Estado de classe,

[...] no sentido de que o governo volta-se em primeiro lugar, para a garantia da rentabilidade dos capitais; que é, todavia, considerada como premissa do emprego e da promoção do trabalho assalariado, que se torna em última instância, o objetivo do Estado-providência. (FARIAS, 1996, p. 32)

Essa dinâmica, em termos políticos e sindicais, resultou numa resolução reguladora favorável a todos os agentes que personificavam as relações conflituais existentes na economia, ou seja, os governos dos Estados identificados com tal proposta passaram a agir tanto sobre o trabalho quanto sobre o capital, por meio de medidas intervencionistas, nos planos da produção e da circulação, com o objetivo de tornar as relações entre capital e trabalho mais pacíficas e menos violentas.

Nesse sentido, o novo regime "surge" como um verdadeiro achado do capitalismo, já que, pressionado pela existência de um bloco socialista, apresenta-se como uma estratégia de desenvolvimento baseada no crescimento da produtividade nos ramos de bens de consumo e no considerável aumento do poder aquisitivo dos trabalhadores. 
Desse modo, para os analistas da "escola de regulação" não seria possível a existência de um regime fordista de acumulação intensiva sem a compatibilização da dinâmica da acumulação e valorização capitalista com a garantia de direitos políticos e sociais mínimos para a classe trabalhadora.

Nesse ponto, partindo de uma outra perspectiva e valendo-se da categoria do antivalor, Oliveira (1988) explicita como se constituiu a época de ouro do capitalismo que, marcada pela adoção de políticas econômicas de caráter expansivo, estimulou as altas taxas de crescimento econômico, o pleno emprego e a constante ascensão dos níveis de vida da maioria da população. Assim, a sociabilidade capitalista, mediante o fundo público, ampliou uma gama de valores, de riqueza social que não se constituiu em capital, mas que além de subsidiar diretamente o capital privado, favoreceu-o subsidiando indiretamente a reprodução da força de trabalho, através da assistência da população por meio das políticas sociais, como forma de desonerar o capital dessa tarefa. A rigor o modelo objetivava em última instância evitar a tendência inerente ao capitalismo, à queda da taxa de lucro.

Por sua vez, isso possibilitou aos capitalistas investirem no desenvolvimento tecnológico, ao mesmo tempo em que permitiu se produzir uma imensa gama de bens e serviços públicos como antimercadorias sociais e uma certa desmercantilização da reprodução da força de trabalho.

Dessa forma, o progresso alcançado na "democracia do trabalho", nas economias fabris ocidentais, principalmente no período que se seguiu ao término da Segunda Grande Guerra, resultou da implantação de uma estratégia que combinou o taylorismo na produção, o fordismo no planejamento político e o keynesianismo no planejamento econômico, ou seja, da combinação específica de organização do trabalho (baseado na passividade, na disciplina e na hierarquia) e de regulação nacional (baseado no acordo entre o patronato, os sindicatos e o Estado), favorecendo, assim, o progresso, tanto sob o aspecto material como sob os aspectos da cidadania, da constituição, da soberania etc. (FARIAS, 1996, p. 40)

Foi nesse cenário que os regimes social-democratas se legitimaram nos principais países europeus ao incorporarem ao capitalismo aspectos da planificação socialista, mediante a intervenção do Estado na economia, 
levando parcelas significativas do movimento operário a suporem que definitivamente o capitalismo teria se reconciliado com os ideais democráticos e resolvido, de uma vez por todas, as contradições que anteriormente os separavam. ${ }^{7}$

A organização estatal daí derivada, alicerçada no compromisso social entre o empresariado, os sindicatos de trabalhadores e o governo, ao promover políticas públicas com vistas à construção e consolidação do chamado "Estado de bem estar", visava com isso a "estabilidade no emprego, políticas de renda com ganhos de produtividade e de previdência social, incluindo seguro desemprego, bem como direito à educação, subsídio no transporte etc." (FRIGOTTO, 1995, p. 70)

Todavia, o Estado que surgiu como desdobramento dessa estratégia não significou uma mudança estrutural da sociedade capitalista, à medida que tal organização estatal "não alterou as relações econômicas e políticas de poder, não transformou o modo privado de produção lucrativa no trabalho público destinado à solução das necessidades humanas" (OFFE, s/d, p. 212), o que permite inferir que o Welfare State, antes de ser um tipo de sociedade utópica do trabalho, se mostrou como "o mais generoso agente assegurador das grandes empresas comerciais na curta, mas gloriosa história do capitalismo" (OFFE, s/d, p. 214).

Levando em conta todos os componentes básicos acima referidos, torna-se possível inferir, a partir da leitura de Huw Beynon sobre o estudo específico de um tipo de Estado de Bem-Estar, o inglês, que

[...] esses arranjos institucionais tinham uma certa força: de um lado porque permitiam a preservação e reprodução de um modo de vida dentro de um contexto de relações desiguais de poder, de outro, porque possibilitavam imprimir a marca dos trabalhadores na sociedade e no Estado. (1995, p. 73)

Desse modo, é a presença das massas no seio dos Estados capitalistas que assegurará os efeitos duradouros provenientes da elevação do gasto público, ampliando aqueles de natureza social.

Entretanto, o compromisso de classe daí derivado só se sustentou à medida que a economia se manteve em expansão. Quando essa passou a apresentar claros sinais de estagnação o intercâmbio de bens passíveis de 
serem permutados no mercado político competitivo como, por exemplo, bemestar material em troca de legitimidade política, se tornou mais trabalhoso e o consenso, tão caro ao modelo, começou a desgastar-se. (NETTO, 1993, p. 69)

Uma vez concluído que foi a estagnação das economias ocidentais, a partir do modelo de desenvolvimento adotado, que se constituiu na principal causa que levou à crise de legitimidade do Estado-providência, faz-se necessário analisar as principais características de tal modelo, procurando-se, assim, situar as raízes dessa crise.

\section{APOGEU E CRISE DO FORDISMO}

Nas últimas três décadas do século passado se observou, nas economias centrais, uma série de transformações no processo de produção capitalista, com rebatimentos importantes nos países periféricos, em particular nos da América Latina. Tais mudanças, que tomaram a forma de uma profunda reestruturação industrial, se apresentaram como respostas à crise do modelo de desenvolvimento adotado pelos países capitalistas centrais, tendo como objetivo último restabelecer o dinamismo e a estabilidade econômica e social vivenciada por esses países no segundo pós-guerra.

Após a Segunda Guerra Mundial, o regime de acumulação intensiva, centrado no consumo de massa, pôde generalizar-se justamente porque um novo modo de regulação, monopolista, havia incorporado a priori na determinação dos salários e dos lucros nominais, um crescimento do consumo popular em proporção aos ganhos de produtividade. (LIPIETZ, 1988, p. 59)

Entretanto, em que pese o sucesso desse modelo de acumulação durante a sua fase áurea, principalmente nos anos 1950 e 1960, o fordismo ${ }^{8}$ (como foi chamado o modelo) progressivamente passa a mostrar seus limites, até mesmo do simples ponto de vista organizacional, sem falar dos seus limites sociais. 
Logo, em primeiro lugar, é necessário se definirem as principais características do fordismo para, em seguida, se situarem os limites desse modelo de desenvolvimento, os quais levaram à crise que assolou as economias centrais nas últimas três décadas do século $X X$.

Uma vez adotada essa premissa, um modelo de desenvolvimento deve ser analisado sob três aspectos, a saber: 1) o regime de acumulação; 2) o modelo de regulação ${ }^{9}$ e 3) o paradigma tecnológico.

O primeiro, o regime de acumulação, diz respeito aos princípios que governam a evolução da organização do trabalho. Assim, denomina-se

[...] regime de acumulação aquele modo de re-alocamento sistemático do produto que rege, num longo prazo, uma certa adequação entre as transformações das condições da produção e as transformações das condições de consumo. Um tal regime de acumulação é dado por um esquema de reprodução que descreve, período por período, a alocação do trabalho social e a repartição dos produtos entre os diferentes departamentos da economia. Por departamentos, entende-se uma partição do conjunto produtivo considerado, partição que se adapta ao problema da reprodução e da acumulação, abstraindo-se de qualquer consideração de ordem técnica em termos de trabalho concreto. $O$ esquema de reprodução é, de algum modo, o esqueleto do regime de acumulação, o marco matemático de sua coerência social. (LIPIETZ, 1988, p. 48)

A rigor, um regime de acumulação pode ser extensivo ou intensivo, conforme se verá:

Um regime de acumulação pode ser principalmente extensivo ou intensivo, vale dizer que a acumulação capitalista é dedicada principalmente à expansão da produção, com normas produtivas idênticas, ou, no outro caso, ao aprofundamento da reorganização capitalista do trabalho ("subsunção real" do trabalho ao capital), geralmente no sentido de uma maior produtividade e de um maior coeficiente de capital. (LIPIETZ, 1988, p. 48)

Por modelo de regulação se entende "o conjunto de regras interiorizadas e de procedimentos sociais, que incorpora o social nos comportamentos humanos" (LIPIETZ, 1988, p. 30), ou seja, são as normas, hábitos, procedimentos, instituições que agem como forças coercitivas ou incentivadoras para que os agentes privados se conformem com determinado regime de acumulação, de tal modo que este regime "aparece como o resultado macroeconômico de um modo de regulação, tendo por base um modelo de industrialização" (LIPIETZ, 1988, p. 30). Já por modelo de industrialização (ou paradigma tecnológico) deve-se entender os princípios que governam a evolução da organização do trabalho. 
Nesse sentido, uma vez definidas as principais características apresentadas por um modelo de desenvolvimento, é pertinente analisar o fordismo, que foi o modelo de desenvolvimento dominante ao longo do século $\mathrm{XX}$.

Quanto ao paradigma tecnológico, o fordismo subsume o que se convencionou chamar de "revolução taylorista" ou taylorismo. Essa forma de organização científica do trabalho, idealizada por Frederick Taylor, disseminada nos EUA e, parcialmente na Europa, nos anos vinte do século passado, surge a partir do segundo grande ciclo da expansão industrial capitalista, oriunda das grandes transformações engendradas pela Segunda Revolução Industrial ${ }^{10}$, o que exigiu a introdução de novos instrumentos de trabalho e a redefinição do processo de trabalho para atender às exigências da produção, impulsionando a constituição de um novo padrão industrial e tecnológico.

Essa "revolução" tratava "(...) de no processo de trabalho, tirar das coletividades operárias seu Know-how, que foi depois sistematizada pelos engenheiros e técnicos através dos métodos da 'organização científica do trabalho"' (LIPIETZ, 1988, p. 50), ou seja, uma das características principais do taylorismo foi a sua capacidade de expropriar os conhecimentos técnicos acumulados pelo trabalhador.

Assim, o operário de métier, que antes detinha o controle relativo sobre as técnicas de produção e condições de trabalho, com a introdução desse método teve subtraída essa capacidade que foi então incorporada ao processo de produção.

O método fundado por Taylor tinha dois objetivos principais: primeiro, generalizar mais rapidamente o método de trabalho aparentemente mais eficaz, elevando assim a produtividade do trabalho e, segundo, através do conhecimento preciso do tempo de cada operação, controlar com maior rigor o ritmo de trabalho dos operários.

Entretanto, faltava a incorporação daquele conhecimento sistematizado ao sistema automático de máquinas que ditavam o modo operacional aos operários expropriados de sua iniciativa, e isso foi possível graças ao fordismo. 
Logo, o que vai diferenciar o fordismo do taylorismo é que naquele as próprias normas são incorporadas ao dispositivo da maquinaria, isto é, é a linha de montagem que vai ditar a operação requerida e o tempo necessário para a sua efetivação.

No que se refere ao trabalho qualificado dentro dos complexos taylorizados, e depois fordizados, se observa que a presença de operários qualificados ainda permanece, sendo indispensável em todos os níveis, principalmente nos segmentos "para trás" deste complexo, naqueles onde se realiza a famosa incorporação, isto é, naqueles onde se produzem os bens de capital industrial, máquinas-ferramentas etc., que são o "coração" do dispositivo produtivo. (LIPIETZ, 1988, p. 51)

As principais características do regime de acumulação adotadas pelo modelo fordista eram a sua grande produtividade e seu alto coeficiente de capital fixo per capita (acumulação intensiva), bem como um crescente consumo de massas.

Em relação ao primeiro aspecto é importante observar que os investimentos em capital fixo só se sustentavam à medida que o fordismo obtinha altos ganhos de produtividade. À medida que esses ganhos foram decrescendo o modelo começou a ruir.

Quanto ao aspecto do consumo de massas, pode-se considerar como sendo, ao lado do taylorismo, um dos pilares mais importantes do regime fordista, uma vez que garantia a legitimidade do sistema.

Isso remete à questão do modo de regulação que caracterizava o fordismo, onde se destaca o papel do Estado. Assim, o que prevaleceu foi a regulação monopolista dos salários, ou seja, através de acordos coletivos constringentes para o conjunto dos empregadores de um ramo e de uma região de produção, de um salário mínimo fixado pelo Estado, cujo poder aquisitivo cresceu no decorrer do tempo, bem como de um sistema de previdência social, financiado por contribuições obrigatórias, a garantir para todos os assalariados uma renda permanente (LIPIETZ, 1988, p. 53), foi possível que o crescimento geral da produtividade se refletisse na elevação do poder aquisitivo dos assalariados. 
Porém, se anteriormente as crises do capitalismo eram de superprodução, como a ocasionada pela aplicação do taylorismo no processo produtivo no começo do século passado, quando os ganhos de produtividade, em não sendo incorporados aos salários, provocaram a crise de superprodução do final dos anos 1920, a crise atual, da acumulação intensiva, aparece com uma crise de rentabilidade, ao contrário da crise de 1930 que era de superprodução, isto é, a partir de um determinado momento, os ganhos de produtividade, em não compensando o aumento da composição técnica do capital, implicou rebaixamento da taxa média de lucros.

Logo, o aumento da produtividade, operado através do desenvolvimento de máquinas e equipamentos cada vez mais sofisticados, que levaram a um aumento substancial da taxa de capital fixo per capita, gerou com isso uma crise de rentabilidade desse modelo.

Como se pode observar, as raízes dessa crise podem ser encontradas nos próprios princípios tayloristas, nos quais o modelo se baseou. A rigor, ao expropriar a iniciativa dos trabalhadores e ao repassar a tarefa de aumentar a produtividade para os setores de Organização e Métodos, sob responsabilidade dos engenheiros e técnicos, o aumento desta produtividade só foi possível através do desenvolvimento de máquinas mais complexas, operadas por trabalhadores cada vez menos qualificados. Tal situação gerou o aumento da taxa de capital fixo per capita, que a partir de determinado momento já não foi compensado pelo aumento da produtividade, levando à crise de rentabilidade.

Diante dessa crise a resposta do capital foi, num primeiro momento, a internacionalização da produção. Esse movimento, decorrente da própria lógica do fordismo e da sua crise então latente, visou "a busca de ganhos de produtividade através da ampliação da escala de produção, e a procura por regiões oferecendo salários mais baixos". (LIPIETZ, 1988, p. 88)

Esse "extravasamento" dos sistemas produtivos por fora das fronteiras nacionais só foi possível, do ponto de vista do processo de trabalho, porque o fordismo permitia uma segmentação, uma repartição em três níveis: 1) a concepção, a organização dos métodos e a engenharia tornadas autônomas; 2) a fabricação qualificada, exigindo uma força de trabalho 
adequada; e 3) a execução e a montagem desqualificadas, não exigindo em princípio nenhuma qualificação. (LIPIETZ, 1988, p. 89).

Desta forma, à antiga divisão horizontal do trabalho entre setores (primário e secundário), se sobrepôs uma segunda divisão, vertical, entre níveis de qualificação dentro de um mesmo ramo industrial.

A adoção dessa estratégia pôde seguir duas lógicas diferentes, dependendo da forma como se articulou com o regime de acumulação central: a "taylorização primitiva" e o "fordismo periférico"11".

O primeiro, o taylorismo primitivo, é entendido como

[...] um deslocamento de determinados segmentos de circuitos de ramos/setores, para Estados que gozam de uma alta taxa de exploração (salário, duração e intensidade do trabalho), cujos produtos são reexportados principalmente para o centro. (LIPIETZ, 1988, p. 92)

As regiões mais representativas dessa estratégia eram as zonas francas da Coréia e Taiwan, assim como os "Estados-feitorias" da Ásia (Singapura, Hong-Kong), em que a participação das mulheres no total dos empregos chegava a $80 \%$, além do que esta lógica objetivava extorquir a mais-valia máxima de uma força de trabalho que ninguém estava preocupado em reproduzir regularmente, em função da reserva inesgotável dessa força de trabalho.

\section{Quanto ao fordismo periférico ${ }^{12}$}

- trata-se de um fordismo autêntico, com um verdadeiro processo de mecanização e um acoplamento da acumulação intensiva e do crescimento dos mercados do lado dos bens de consumo duráveis.

- permanece periférico no sentido de que, primeiramente, nos circuitos mundiais dos ramos produtivos, as estações de trabalho e as produções correspondentes aos níveis da fabricação qualificada e, principalmente, da engenharia, permanecem em ampla medida exteriores a esses países. (LIPIETZ, 1988, p. 97)

O seu surgimento está condicionado à existência de um mercado capaz de absorver pelo menos parte da produção, pressupondo o consumo das classes médias modernas locais, o acesso parcial dos operários do setor fordista aos bens de consumo popular duráveis. Nesta categoria podem ser incluídos os "Novos Países Industrializados" (NPI's) como a Coréia, México, Brasil, Espanha etc. 
No entanto, a internacionalização da produção não se constituiu em saída para a crise de rentabilidade do fordismo. Isso porque se, por um lado, esse processo de internacionalização, que objetivava resolver os problemas da rentabilidade por meio da redução do custo da força de trabalho e da ampliação da escala de produção, num primeiro momento se mostrou satisfatório, por outro, essa solução fez com que o problema surgisse pela demanda, pelo colapso do consumo.

Vale dizer que esse processo de internacionalização da produção, principalmente por meio da adoção do "taylorismo primitivo" na periferia do capitalismo, ao provocar a diminuição do número de postos de trabalho e a estagnação dos salários nos países desenvolvidos, levou à crise de consumo das economias centrais, que não foi compensada pelo aumento do consumo ocorrido na periferia. Isso, por sua vez, explica o processo de reestruturação industrial ocorrido naqueles países.

Nesse sentido, a estagnação dos rendimentos, agravada ainda por situações conjunturais, como a crise do petróleo, considerada uma das causas da recessão econômica que levou ao esgotamento do padrão de consumo fordista, dá a devida compreensão das mudanças e transformações na configuração do processo de trabalho promovidas no âmbito das economias centrais, de modo que, ao novo modelo econômico requerido pelo grande capital, correspondeu um outro paradigma produtivo, tecnológico e organizacional.

Desse modo, as implicações decorrentes do processo acima descrito sobre a acumulação manifestaram-se de duas formas: a primeira, por meio da inflação do salário direto, que refletiu negativamente sobre a taxa de mais-valia e, a segunda, pelo endividamento do Estado, que, por apresentar um caráter cumulativo, repercutiu de forma negativa no aprofundamento da crise, pois é nas fases depressivas que mais crescem as demandas pelos serviços públicos.

Com o esgotamento dos ganhos de produtividade provocado pela crise do padrão de acumulação rompe-se o pacto entre os "parceiros" sociais envolvidos, levando as classes dominantes desses países e os partidos socialdemocratas no poder a optarem, cada vez mais, por uma regulação da 
economia e da própria sociedade pelas leis do mercado, em detrimento da ação social preventiva e reguladora do Estado.

A rigor, o significado histórico das transformações ocorridas nesse tipo de ordenamento sócio-político sinaliza para prerrogativas de caráter antidemocrático, postas pelo recente desenvolvimento da ordem capitalista, à medida que indicam o retorno, décadas depois, às velhas cátedras do liberalismo, agora travestido com nova roupagem. Isto significa que a metamorfose sofrida pelo capitalismo restaurou "o mercado como instância mediadora societal elementar e insuperável e uma proposição política que repõe o Estado mínimo como única alternativa e forma para a democracia". (NETTO, 1993, p. 77)

Porém, não é somente a crise do Estado do bem-estar, que tem início na passagem da década de sessenta à de setenta, o elemento explicativo da crise global contemporânea e da ofensiva neoliberal em curso, como também a falência dos padrões societários configurados pelos países do chamado socialismo real.

A falência dos Estados socialistas ofereceu ao arsenal do neoliberalismo a comprovação da insustentabilidade de uma economia planejada, enquanto que a crise do Welfare State ofereceu o argumento para colocar em dúvida a eficiência estatal na indução do crescimento econômico e na promoção do bem estar social. (NETTO, 1993)

A partir dos motivos expostos, a teoria neoliberal erigiu o mercado como realidade empírica central promotora de um duplo papel na conformação de uma sociedade livre, de modo que, tal teoria passou a defender

[...] que qualquer mecanismo de coordenação consciente da
atividade econômica - quer se expresse por meio de uma direção
centralmente planejada como foi o caso do socialismo real, quer
através de uma regulação socialmente dirigida do mercado através
do chamado Estado de bem-estar social - é incapaz de promover,
com eficiência, a produção e distribuição da riqueza. (TEIXEIRA,
1996, p. 231)

Contudo, à medida que a crise se mostrou como de caráter estrutural, atingindo diretamente a relação entre capital e trabalho, ela também se refletiu sobre o aparelho estatal, fundamentalmente no que tange ao financiamento do processo de acumulação como na efetivação de políticas 
necessárias à reprodução da força de trabalho, exigindo uma profunda mudança tanto no nível da organização do processo produtivo quanto na forma de intervenção do Estado.

O novo padrão daí emergente requereu um completo reordenamento das funções estatais, de modo que, com a adoção das políticas de cunho neoliberal, o Estado agora redefinido assumiu a função de criador das condições sistêmicas de valorização para os setores de ponta, objetivando melhores condições de competir no mercado internacional, o que, por sua vez, significou garantir infra-estrutura básica, força de trabalho qualificada, recursos científicos e tecnológicos, subvenções, condições de mercado etc., para os grandes grupos financeiros e industriais transnacionais agora detentores de um poder maior sobre a definição das políticas e ações estatais. (MOURA, 1996)

\section{CRISE E MUDANÇA NO MUNDO DO TRABALHO: OS NOVOS PARADIGMAS E A CONSTITUIÇÃO DE UM NOVO TRABALHADOR}

Com a crise da etapa fordista do capital, a reestruturação da produção se impôs enquanto um imperativo necessário ao combate à rigidez que caracterizava esse modelo de desenvolvimento ${ }^{13}$. Tais inovações foram vistas como possibilitadoras de incrementar a flexibilização do sistema produtivo, além de mostrarem-se indispensáveis à recuperação da capacidade de crescimento da economia.

De fato, é no quadro de enfrentamento da crise do padrão de acumulação anterior que a revolução tecnológica e informacional aparece como uma resposta global do sistema à crise do modelo de acumulação, engendrando entre outros elementos um novo e intenso ciclo de globalização econômica. Essa "revolução" ampliou consideravelmente o poder dos oligopólios, provocado pelas fusões, joint ventures, diminuição de plantas industriais etc.

Tal processo que ocorre no plano da organização industrial marcado por um caráter global - deve ser entendido inserido num "dado estágio de desenvolvimento do capitalismo, que se caracteriza por um aprofundamento 
da concentração do capital e de uma nova forma de organização das empresas pela financeirização e pela fragmentação". (MARQUES, 1996, p. 136)

Daí as interpretações dadas ao papel desempenhado pelas inovações tecnológicas e as políticas de desregulamentação na nova conjuntura serem, num primeiro momento, a de facilitar a mundialização ${ }^{14}$, e, num segundo momento, a de conformar as novas normas de produção. Assim, o eixo condutor do processo de acumulação aparece projetado na propriedade inerente dos meios de conhecimento, objetivado na utilização da automação e da informática.

Porém, o modelo japonês, o toyotismo, por ser portador de um modo de extração de ganhos de produtividade que correspondeu, de forma mais fiel, ao atual estágio alcançado pelo capitalismo, e por assentar-se em novos métodos de organização do trabalho distintos dos padrões fordistas, ao se apresentarem mais flexíveis e moduláveis ${ }^{15}$, foi aquele que demonstrou maior tendência à universalização.

A conseqüência direta dessa processualidade pode ser verificada, embora de forma não homogênea, no questionamento, fratura ou mesmo rompimento do compromisso social e das relações/instituições econômicas, sociais e políticas definidas quando da constituição e expansão do Estado de bem-estar, das políticas econômicas de viés keynesiano e do crescimento estável. (MATTOSO, s/d)

A rigor, o desmonte das funções eqüitativas do Estado, com a eliminação dos direitos sociais, o desmonte da seguridade, desregulamentação e arrocho salarial, resultou na ampliação da desigualdade e da exclusão que se materializaram nos altos níveis de desemprego estrutural, conseqüentemente, em sindicatos mais débeis frente à ação patronal, levando-os à perda quase absoluta do seu poder político e de representação.

Nesse sentido, o pós-fordismo - como passaram a ser denominadas as transformações no mundo do trabalho e em especial o toyotismo - buscou uma nova forma de regulação assentada fundamentalmente na flexibilização do processo produtivo, na intensificação do trabalho, no modelo cooperativo de 
organização dos sindicatos, na horizontalização da produção etc., para tentar superar a crise de acumulação do padrão anterior.

Com a introdução dessas inovações ao mesmo tempo em que se elevaram os ganhos de produtividade dos capitalistas, operou-se em sentido contrário a substituição do trabalho vivo por trabalho morto, de modo que o impacto ocasionado por tais experiências da acumulação flexível - em especial a japonesa - à classe trabalhadora, teve em comum a flexibilização dos direitos trabalhistas, de modo a dispor da força de trabalho em função direta das necessidades do mercado consumidor.

Assim, para a efetiva flexibilização do processo produtivo, tornou-se necessária a flexibilização do trabalho, uma vez que o "toyotismo estrutura-se a partir de um número mínimo de trabalhadores, ampliando-os, através de horas extras, trabalhadores temporários ou subcontratados, dependendo das condições de mercado". (ANTUNES, 1995, p. 28)

A emergência da nova forma de organização do trabalho apontou para a constituição de um novo trabalhador, de caráter polivalente, ou melhor, a adoção dos novos paradigmas além de promover o desemprego tecnológico, requereu a alteração do perfil da qualificação profissional, exigindo, assim, por sua vez, o redirecionamento das ações estatais, visando à consolidação de novas competências na força de trabalho; por outro lado, face ao crescente defensismo do movimento sindical frente às novas transformações no mundo do trabalho surge "uma massa de trabalhadores que perdem seus antigos direitos e, não se inserindo de forma competitiva (...) no novo paradigma tecnológico, tornam-se desempregados". (MATTOSO, s/d, p. 524)

A exigência de um novo tipo de qualificação pelos setores chaves da produção se deu à medida que a empresa pós-fordista, altamente competitiva e flexível, necessitou desenvolver a iniciativa, a cognição, a capacidade de raciocínio lógico e a criatividade do trabalhador para possibilitar respostas imediatas no manejo das novas tecnologias.

Com o surgimento do novo padrão de desenvolvimento ampliou-se a diferenciação entre os trabalhadores, levando a uma situação em que os "beneficiados" pelo processo de reestruturação dispõem de um alto nível de 
formação, escolar e técnica, proveniente de uma escola pública de qualidade, garantias no emprego, com uma relativa estabilidade, pequena diferenciação salarial e pouca rigidez na definição dos postos de trabalho, trabalho em equipe, contratações coletivas (Suécia e Itália), discussão e negociação sindical quanto a processo de trabalho e inovação, enquanto que os excluídos do processo, por se situarem à margem dessas garantias, tiveram o seu trabalho desqualificado, regidos por relações muitas vezes precárias e não padronizadas. (MATTOSO, s/d, p. 524)

Nesse contexto, a reestruturação produtiva - muito mais evidente nos países centrais - aponta para uma descomunal reconcentração do capital que, por conseguinte, deve ampliar o poder financeiro, comercial e produtivo dos grandes grupos internacionais. Contudo, vale salientar que, se nos países centrais a implantação de tais modelos mostrou nitidamente o seu caráter excludente com o aprofundamento das desigualdades sociais, para os países periféricos a transposição mecânica dessas experiências tem se apresentado como um verdadeiro desastre, à medida que a nova fase do capitalismo, em sua ação globalizante,

[...] está causando um verdadeiro flagelo, sucateando precocemente capacidade produtiva e infra-estrutura (...). Por outro lado, o debilitamento do Estado, que já era acentuado com a "crise da dívida", aumentou ainda mais, com as políticas de ajustes neoliberais, desregulamentações, privatizações, exaustão da capacidade de planejamento e incapacitação da política econômica. A esses Estados nacionais pouco tem restado fazer para escapar de uma "reação passiva". Isso tudo está agravando sobremodo a atual crise social. (CANO, 1996, p. 134)

Nesse sentido, a forma "globalizante" que assume o processo de acumulação promoveu uma outra configuração do perfil da força de trabalho por meio de novos processos de qualificação/desqualificação - ao requerer mudanças nos requisitos educacionais desses trabalhadores -, reforçando e aperfeiçoando a subsunção do trabalho à lógica do capital, como também exigindo a redefinição da política educacional do Estado nos países centrais.

\section{O CASO BRASILEIRO: ANTECEDENTES HISTÓRICOS}


No que concerne à aplicação da automação e da informatização na indústria brasileira, esse processo se apresentou de forma mais intensa a partir do início da década de 1990. Entretanto, é importante esclarecer que, mesmo considerando uma série de políticas de ajuste e modernização tecnológica que presidiram tal metamorfose na economia ${ }^{16}$, particularmente no seio das empresas - no final dos anos 1970 - e que possibilitaram mais claramente a compreensão da aplicação dessas inovações, não é o objetivo aqui retomar de maneira detalhada todo o processo, dados os limites do texto.

Sendo assim, embora aqui nesse ensaio se tome como referência o texto de Leite "Reestruturação produtiva, novas tecnologias e novas formas de gestão da mão-de-obra", não se considerará totalmente a periodização sistematizada pela autora, que identifica três diferentes momentos do processo de modernização tecnológica no país. Assim, aqui será destacado apenas o terceiro período, que se inicia nos anos 1990 , fase a partir da qual foi detectado um maior esforço dos capitalistas no sentido de acompanhar a tendência mundial de flexibilização da produção e do trabalho.

De todo modo, é importante ressaltar que tal processo tem início induzido por dois fenômenos distintos, mas que devem ser analisados de maneira integrada e que são respectivamente os novos padrões de competitividade internacional exigidos pelo capital e um conjunto de mudanças econômicas, políticas e sociais ocorridas internamente no país.

Isso significa dizer que, verdadeiramente, não foi só a crise econômica o aspecto relevante da mudança de perfil tecnológico e de gestão da força de trabalho do parque industrial brasileiro, mas igualmente a existência de duas outras motivações básicas: a primeira, o processo de democratização do país, e a segunda, o ressurgimento do movimento sindical combativo.

É nesse contexto marcado pelos aspectos supracitados que os capitalistas são compulsoriamente obrigados não somente a substituir as políticas repressivas da força de trabalho no interior das fábricas por outras mais compatíveis com a flexibilização do trabalho (just in time, CCQ, Kanban, administração participativa etc.), como também a introduzir paulatinamente 
novos equipamentos de base microeletrônica, visando a novos padrões de competitividade e qualidade. (LEITE, s.d., p. 564)

Convém destacar que no início da década de 1990, em razão da abertura econômica adotada pelo governo Collor e pela retração do mercado interno, a modernização forçada assumiu o caráter de uma verdadeira reestruturação produtiva, à medida que, pressionadas pela concorrência internacional, muitas indústrias optaram pela adesão ao Programa Brasileiro de Qualidade e Produtividade ${ }^{17}$, com o intuito de buscar métodos mais eficazes de produção, por conseguinte, portadores de instrumentos competitivos que permitissem a indústria brasileira a manter - e até ampliar - sua inserção no mercado internacional.

Vale sublinhar que Leite, baseada em estudos realizados sobre as mudanças ocorridas na organização industrial, ressalta que

[...] diferentemente de períodos anteriores, em que inovar significava,
para muitas empresas, comprar equipamentos e/ou introduzir
"pacotes" e "programas" (g.a.) organizacionais ou de motivação, que
eram implantados em setores das empresas, muitas vezes por
iniciativa deste ou daquele departamento, com resultados
heterogêneos, a partir do final dos anos oitenta, passamos a
encontrar um conjunto cada vez maior de empresas em processo de
profunda reestruturação a partir de uma decisão da direção,
introduzindo todo um conjunto de inovações articuladas entre si.
Esses esforços de reestruturação mais integrados se manifestaram a
partir da introdução de algum tipo de Programa de Qualidade Total.
(LEITE, s.d., p. 574)

Diante do exposto, os investimentos em novas técnicas de organização do trabalho que, em última instância, tendem a aumentar a capacidade de produção e, ao mesmo tempo, a diminuir o custo de produção, além de serem pré-requisitos fundamentais para a introdução de equipamentos e tecnologia mais avançada, se explicam em decorrência do fato de a indústria brasileira desperdiçar algo em torno de 40 bilhões de dólares, não só pela baixa produtividade, mas também pelos altos custos da produção. (BORGES, 1990, p. 50)

É importante assinalar que a introdução dessas novas técnicas organizacionais mesmo que perspectivem uma maior participação no controle dos processos de trabalho e em novas possibilidades de desenvolvimento pessoal, resultam também num maior controle do capital sobre os operários, já que a implementação das novas políticas de gestão da força de trabalho 
embora, aparentemente, se mostrem "humanizadoras" das relações entre capital e trabalho, busquem incessante a diminuição dos conflitos no interior da fábrica $^{18}$, na verdade, objetivam a modernização da exploração pelo envolvimento cooptado dos trabalhadores, possibilitando ao capital apropriar-se do saber e do fazer do trabalho. ${ }^{19}$

De outra parte, as mudanças que estão se processando na organização industrial vêm acompanhadas de uma nova segmentação da força de trabalho, de novos padrões de qualificação, da terceirização e do desemprego estrutural. Dessa forma, tendencialmente são as mudanças relacionadas à redução dos custos da produção - ligadas à descentralização, via a externalização de atividades - que caracterizam o esforço de modernização por parte dos capitalistas. Assim sendo, embora a tendência à terceirização seja dirigida predominantemente àqueles setores ligados aos serviços, alguns estudos têm apontado para a crescente participação de empresas terceirizadas nos setores ligados à produção.

Os impactos dessa tendência sobre a força de trabalho, nos setores não essenciais da produção, têm apontado para uma crescente precarização das condições do emprego e desqualificação profissional do trabalhador, uma vez que é revelador o fato de os trabalhadores que são submetidos à terceirização terem salários e benefícios sociais mais baixos, jornadas de trabalho mais extensas e estafantes - daí a menor qualificação requerida -, além de menor segurança e maior insalubridade nos locais de trabalho; isso sem levar em consideração que a externalização das atividades pode significar o comprometimento da qualidade dos serviços prestados. (LEITE, s/d, p. 575)

Entretanto, apesar de tal processo se apresentar ainda de uma forma muito heterogênea, é um fato evidente que os capitalistas brasileiros paulatinamente envidam esforços no sentido de acompanhar os padrões internacionais de modernização do processo produtivo, pelo menos no setor dinâmico da acumulação do capital. Assim, embora a questão remeta a uma polêmica discussão relacionada ao atual processo de reconversão da produção e aos novos requisitos de educação demandados por esse processo, faz-se necessário analisar o processo de reformas na educação básica e profissional ocorrido na última década do século passado, que visava adequar o modelo 
educacional ao fenômeno da reestruturação produtiva em curso num país periférico como o Brasil.

\section{REFERÊNCIAS}

AGUIAR, Flávio; MORAES, Ignez Navarro de; FELIX, Maria de Fátima. Diretrizes para uma política de formação profissional da CUT. Caderno ANDES, n. 10, Brasília, out. 1993.

ANTUNES, Ricardo. Adeus ao trabalho? Ensaio sobre as metamorfoses e a centralidade do mundo do trabalho. São Paulo: Cortez; Campinas: Universidade Estadual de Campinas, 1995.

BEYNON, Huw. A destruição da classe operária inglesa? Revista Brasileira de Ciências Sociais. São Paulo: ANPOCS, n. 27, ano 10, fev. 1995.

BORGES, Altamiro. Novidades na exploração dentro das fábricas. Revista Princípios, n. 22, ago./set./out. 1990.

BÓRON, Atílio. Estado, capitalismo e democracia na América Latina. Rio de Janeiro: Paz e Terra, 1995.

CANO, Wilson. Notas sobre o imperialismo hoje. Crítica Marxista. N. 03. São Paulo: Brasiliense, 1996.

FARIAS, Flávio Bezerra de. O Estado capitalista contemporêneo. Para a crítica das visões regulacionistas. São Paulo: Cortez, 2000.

A modernidade e o Estado regulacionista? In. O Estado capitalista contemporâneo. São Luís, 1996. (mimeo)

FRIGOTTO, Gaudêncio. Formação técnico-profissional: de política social para assistência e alivio da pobreza. Disponível em: <http://www.ilea.ufrgs.br/unitrabalho/boletim/n05/artigos/artigo01.html>. Acesso em: 22 out.2001. 
. Educação e crise do capitalismo real. São Paulo: Cortez, 1995.

LEITE, Márcia de Paula. Reestruturação produtiva, novas tecnologias e novas formas de gestão da mão-de-obra. In. OLIVEIRA, Carlos Alonso et alli (Org.). $O$ mundo do trabalho: crise e mudança no final do século. São Paulo: Página Aberta, [s.d.].

MARQUES, Rosa Maria. Globalização e Estados nacionais. Crítica Marxista. N. 03, São Paulo: Brasiliense, 1996.

MATTOSO, Jorge Eduardo L. O novo e inseguro mundo do trabalho nos países avançados. In. OLIVEIRA, Carlos Alonso et alli (Org.). O mundo do trabalho: crise e mudança no final do século. São Paulo: Página Aberta, [s.d.].

NETTO, José Paulo. Crise do socialismo e ofensiva neoliberal. São Paulo: Cortez, 1993.

OFFE, Claus. Capitalismo avançado e Welfare State. In. CARDOSO, Fernando Henrique, MARTINS, Carlos E. (orgs.). Política e Sociedade. São Paulo: Companhia Editora Nacional, v. 2, [s.d.]. (mimeo)

OLIVEIRA, Francisco de. O surgimento do antivalor: capital, força de trabalho e fundo público. Revista Novos Estudos CEBRAP. São Paulo, n. 22, out./1988.

TEIXEIRA, Francisco José Soares. O mundo "preto-e-branco" do pós-fordismo quanto pior, melhor. Disponível em: <http://www.img.org.br/artigos.html>. Acesso em: 26 jul.2001.

O neoliberalismo em debate. In. TEIXEIRA, Francisco José Soares, OLIVEIRA, Manfredo Araújo de (Orgs.). Neoliberalismo e reestruturação produtiva: as novas determinações do mundo do trabalho. São Paulo: Cortez; Fortaleza: Universidade Estadual do Ceará, 1996. 
${ }^{1}$ Doutor em Educação pelo Programa de Pós-Graduação em Educação da Universidade Federal do Rio Grande do Norte. Professor Adjunto II, lotado no Departamento de Estudos Especializados, da Universidade Federal do Ceará.

2 Mais precisamente o livro de Alain Lipietz, "Miragens e Milagres", obra em que esse autor aborda as várias facetas que levaram a crise do modelo de desenvolvimento fordista.

${ }^{3}$ Por periféricos chamam-se os países nos quais o regime de acumulação dos países capitalistas mais avançados não conseguiu se implantar. (LIPIETZ, 1988, p. 45).

${ }^{4}$ Entende-se por escola da regulação uma corrente de economistas que mantém certa proximidade com o marxismo e tem grande expressão em especial na França.

${ }^{5}$ Este período que vai de 1945 a 1975 corresponde ao que convencionalmente alguns teóricos chamam de os "trinta gloriosos". Tal período foi caracterizado pelo regime fordista de produção e pelo consumo de massa, isto é, pela evolução do poder de compra dos salários e pela rentabilidade do capital, mediados por um sistema de instituições estatais e contratuais. (FARIAS, 1996).

${ }^{6}$ Entende-se por tendência regulacionista politicista aquela para a qual o socialismo (passagem de uma regulação da sociedade - de viés keynesiano - para uma sociedade regulada - gramsciana) resultaria de reformas no capitalismo, que estariam ligadas a algumas ações estatais e contratuais cada vez mais democráticas. Esta, portanto, não nega a luta de classes. Já a tendência regulacionista tecnicista defende que "a crise é uma perda de dinamismo típica da existência burguesa moderna, que pode, entretanto, ser estendida para toda condição humana, inclusive para a dos operários massificados - que se deixam levar passivamente pela derrota burguesa. (...) É a única alternativa, em termos de movimento operário, tornado conformista e oficial, no contexto da modernidade em vigor, onde o motor da história não é mais a luta de classes, mas a técnica". (FARIAS, 2000, p. 65).

${ }^{7}$ Essa guinada da social-democracia levou a uma dissociação entre socialismo e democracia, reforma e revolução, o que a fez renegar suas pretensões transformadoras e o seu projeto de construir uma sociedade socialista, contentando-se com a busca de metas muito mais modestas, como a de tratar de insuflar um espírito mais solidário ao capitalismo monopolista. (BÓRON, 1995, p. 153).

8 É interessante observar que Lipietz (1988, p. 14) chama a atenção dos leitores para o caráter contraditório da expressão "fordismo". Segundo esse autor, "tal como conceitualizado pelos autores dos anos setenta (inclusive ele) dizia respeito a economias nacionais desenvolvidas e relativamente autocentradas". “(...) É um conceito que pretende levantar alguns aspectos de algumas realidades, com intuito de propor uma lógica. (...) é apenas um nome que designa o conceito baseado no caráter evocativo do nome de Henry Ford, cujas práticas, e alguns escritos, antecipavam aquilo que passamos a chamar de "fordismo". Essa evocação (...) é bastante enganosa: a realidade econômica dos países capitalistas avançados do pós-guerra é bastante diferente daquilo que H. Ford recomendava."

${ }^{9}$ Por regulação (palavra oriunda da área da cibernética) entende-se a maneira pela qual um processo contraditório se reproduz de modo regular apesar e através de suas próprias contradições. Deve-se diferenciar de regulamentação que diz respeito a uma decisão do Estado para impedir ou obrigar os agentes a realizar tal ou qual fato. A "regulamentação" pode constituir um meio de se conseguir a "regulação", mas não se constitui no único.

${ }^{10}$ A Segunda Revolução Industrial foi marcada pela descoberta da eletricidade, do motor a explosão, da química orgânica, dos materiais sintéticos, da manufatura de precisão, etc.

${ }^{11}$ Lipietz (1988, p. 15) chama a atenção para o fato de que o "conceito de fordismo periférico não 'cola' perfeitamente a nenhuma realidade empírica", pois, continua o autor, "nenhum país, salvo talvez a Coréia na segunda metade dos anos setenta, pode ser designado como 'um' fordismo periférico". Indica ainda que nem "a França, nem a Itália, nem o Japão foram realmente fordismos, mas o conceito de fordismo permite salientar uma parte do que foi a história econômica desses países nos anos de 1950-1970.”

12 É preciso assinalar que o fato do modelo fordista se desenvolver em certos países periféricos, isso não implica dizer que outros regimes de acumulação vigentes desapareçam. É perfeitamente possível a 
convivência de um modelo fordista periférico com outro regime de acumulação que se apóie no latifúndio.

13 Para a tendência tecnicista “(...) a crise do regime de acumulação intensiva, instalada desde 1945, resulta do fato de que as instituições do fordismo, em vez de impulsionar a regulação que lhe são próprias, transformaram-se num obstáculo ao processo. (FARIAS, 1996, p. 43).

14 Para Marques (1996, p. 136) a mundialização, diferentemente do entendimento dos organismos internacionais, como o BIRD e o FMI, que a apresentam como "a fase atual da economia mundial em que o mundo se apresenta sem fronteiras e as grandes empresas sem nacionalidade", corresponderia a um fenômeno que ocorre, sobretudo na reorganização do capital industrial. Desse modo, a economia mundial passaria a ter uma dependência ainda maior das empresas transnacionais.

15 Teixeira (1996, p. 64) observa que tais características só eram possíveis graças a linearização do processo produtivo, assentada na multifuncionalidade dos trabalhadores.

16 Essas mudanças foram advindas da crise do modelo baseado na substituição de importações que caracterizou o desenvolvimento industrial nesse período. (LEITE, s.d., p. 563).

17 Tal programa criado em 1990, por técnicos do Ministério da Economia e representantes das maiores corporações industriais do país, objetivava a modernização dos métodos de gestão empresarial, como também o treinamento de recursos humanos e o aperfeiçoamento tecnológico. (BORGES, 1990, p. 50).

18 É possível vislumbrar essas mudanças através de uma certa estabilização da mão-de-obra, pelo treinamento do pessoal, pela simplificação das estruturas de cargos e salários e pela diminuição dos níveis hierárquicos. (LEITE, s/d, p. 575).

${ }^{19}$ Esse novo tipo de alienação, própria da nova fase do capitalismo, é aquela em que o trabalhador "deve pensar e agir para o capital, para a produtividade, sob a aparência da eliminação efetiva do fosso existente entre elaboração e execução no processo de trabalho" (ANTUNES, 1995, p. 34).

RECEBIDO EM: 02.06.2011

APROVADO EM: 28.06.2011 